\title{
Конические решетки в устройствах для обеззараживающей обработки зерна
}

\author{
Максименко Владимир Андреевич \\ Северо-Кавказский научно-исследовательский институт механизации \\ и электрификации сельского хозяйства Федерального государственного \\ бюджетного научного учреждения «Аграрный научный центр \\ «Донской» (СКНИИМЭСХ ФГБНУ «АНЦ «Донской») \\ Адрес: 347740, г. Зерноград, Ростовская область, ул. им. Ленина, д. 14 \\ E-mail: elektro_skniimesh.rashn@mail.ru
}

\begin{abstract}
Исходя из ранее выявленной эффективности применения комбинированных обеззараживающих воздействий для обработки семян зерновых культур предложено их выполнение в одном устройстве. Выполнен анализ возможных конструктивных вариантов установок для обеззараживания зерна на основе обработок низкочастотными магнитными полями или электромагнитными полями сверхвысокой частоты в сочетании с воздействием конвективного тепла, по результатам которого сделан выбор в пользу разработки устройства для этапа обработки зерна обеззараживающими газовыми агентами, оснащенного коническими решетками, с разработкой его технологической схемы. Обоснована конструктивно-технологическая схема установки комбинированного обеззараживания семян зерновых культур и разработана методика определения параметров ее элементов и режимов функционирования.Рассмотрены условия рационального соотношения газового и зернового потоков в устройстве и предложены основные математические выражения для определения их расходов. Считая определяющим расход потока зерна в зоне электрофизического воздействия по предложенным выражениям могут определяться основные размеры конических решеток и их расположение относительно друг друга, а также время пребывания зерна под воздействием обеззараживающего газового потока. На основе предложенных выражений возможно также решение обратных задач - подбора параметров потоков для рационального использования имеющихся размеров решеток. Представленные зависимости и методические рекомендации могут применяться при проектировании оборудования для комбинированного электрофизического обеззараживания зерна с использованием конических решеток.
\end{abstract}

Ключевые слова: зерно, газ, поток, решетка, конус, слой, обеззараживание

\section{Введение}

Предыдущими исследованиями (Пахомов, Максименко, Буханцов, \&Ватутина, 2020; Cwiklinski, Hörsten, Lücke, \& Wolf, 2001; Дубровин, 2017; Baсильев, 2018; Андреев, 1987; Пахомов, В.И., Пахомов, А. И., \& Максименко, 2015;Сюсюра, 2003;
Цугленок,Цугленок, \&Шахматов, 1989; Червяков, Курзенков, Циркунов, \& Крупенин, 2008)выявлена эффективность комбинации тепловых, магнитных, высокочастотных электромагнитных и химических обеззараживающих воздействий на зерновой семенной материал. Это позволяет считать выгодным их выполнение одним устройством. $1,2,3,4,5,6,7$

1 Пахомов, А. И. (2014). Отчет о НИР. № 215011250078. Разработка нового технологического процесса высокоинтенсивной обработки сельскохозяйственных материалов с использованием комбинированных электрофизических воздействий и экологически чистых препаратов для их обеззараживания. Зерноград: ФГБНУ СКНИИМЭСХ.

2 Пахомов, А. И. (2015). Отчет о НИР. № 215121620023. Разработка технологии эффективной обработки сельскохозяйственных материалов с использованием обеззараживающих препаратов и комбинированных электрофизических воздействий. Зерноград: ФГБНУ СКНИИМЭСХ.

${ }^{3}$ Пахомов, А. И. (2011). Отчет о НИР. № 104-11.2. Разработка улучшенных энергосберегающих технологий и исходных требований на разработку новых технических средств высокоинтенсивной обработки сельскохозяйственных материалов с использованием комбинированных электрофизических воздействий на основе аналитических и технико-экономических исследований. Зерноград: ГНУСКНИИМЭСХ.

${ }^{4}$ Klaptchuk, P. (2005). CA Patent № 2521786. Procede de destruction des semences. Regina, SK: Furman \& Kallio.

5 Пахомов, В. И., Пахомов, А. И., Буханцов, К. Н., \& Максименко, В. А. (2013). Патент № 2496291 РФ. Способ обеззараживания зерна и семян сельскохозяйственных культур. Зерноград: ГНУ СКНИИМЭСХ Россельхозакадемии.

6 Фисинин, В. И., Лачуга, Ю. Ф., Пахомов, В. И., Пахомов, А. И., \& Буханцов, К. Н. (2015). Патент № 2550479 РФ. Способ комбинированного обеззараживания зерна и семян с использованием электромагнитного поля сверхвысокой частоты. Зерноград: ГНУ СКНИИМЭСХ Россельхозакадемии.

7 Болотов, Н. А., \& Кашкин, Е. Е. (2004). Патент № 2222133 РФ. Способ обеззараживания семян зерновых культур. Воронеж: Воронежский государственный аграрный университет им. К.Д. Глинки, ООО НПФ «Айболит». 
В технологиях обработки зерновых материалов довольно широко используют воздействия на них газообразных агентов. Это, например, сушка, при которой сухой подогретый воздух проходит через слой зерна. Использование при этом озоно-воздушной смеси ускоряет отбор влаги. Сама озоно-воздушная смесь, при различных параметрах ее воздействия, способствует снижению зараженности зерна и улучшает его посевные качества (Голубкович, Тимошек, \& Чеботарев, 2002; Глущенко \& Глущенко, 2003; Голубкович \& Чижиков, 2005; Baskakov, Orobinsky, Gulevsky, Gievsky, \& Chernyshov, 2020; Raila et al., 2006; Андрющенко \& Буханцов, 2007; Максименко, Андреев, Громакова, \& Парапонов, 2009; Пахомов \& Буханцов, 2011; Пахомов, Газалов, \& Буханцов, 2019; Пахомов, Максименко, \& Буханцов, 2013; Буханцов, 2012; Savi, Piacentini, Bittencourt, \& Scussel, 2014).

По отношению к обрабатываемому продукту процессы можно подразделить на непрерывные и периодические. Непрерывные процессы как правило требуют существенно меньших капитальных затрат на технические средства их обеспечения, но достижение технологического воздействия сопряжено с качественным поддержанием режимов что приводит к увеличению затрат на квалифицированный обслуживающий персонал и некоторое увеличение затрат на автоматизацию.

Каждая конкретная ситуация реализации технологического процесса имеет свое наиболее рациональное решение. Рациональность возрастает с увеличением широты выбора, то есть количества возможных вариантов. Для случая обработки зерна газами предлагается вариант в виде устройства непрерывного действия,

в котором путем пересечения потоков зерна и газового агента осуществляется их взаимодействие. Практическая реализация сводится при этом к согласованию двух упомянутых потоков ссохранением тенденций к минимизации и капитальных и эксплуатационных затрат. Из этих соображений представляются выгодными самотечные потоки зерна. Однажды поднятое зерно может проходить несколько зон воздействия. Далее задача сводится к обеспечению характеристик потоков, которые будут соответствовать наилучшим технологическим результатам.

Анализ возможных конструктивно-технологических решений взаимодействия газовых и зерновых потоков. К характеристикам зернового потока относятся его расход, скорость, толщина слоя, форма сечения и его площадь, наличие вза- имного перемещения его зёрен и другие. Газовый поток характеризуется расходом активного агента, который зависит от скорости потока, площади его проходного сечения концентрации в нем активного агента

Скорость обеспечивается в том числе и давлением газа на входе в зерновой поток. Используемые для этого вентиляторы часто не развивают больших давлений, достижение которых довольно затратно. Газовый поток тормозится слоем зерна. Величина торможения, то есть уменьшение расхода потока, напрямую зависит от толщины продуваемого зернового слоя. Уменьшением этой толщины, увеличением площади слоя можно увеличивать расход газового потока до необходимого.

Основное технологическое требование к потоку зерна состоит в обеспечении получения отдельными зернами необходимой, заданной дозы активного агента за время пребывания в зоне пересечения потоком газа. Достижению этого будет способствовать поддержание заданной толщины слоя, одинаковость путей продвижения зерен и одинаковость их времени пребывания под воздействием, что по сумме факторов обеспечит одинаковость усвоения зернами газового агента. Естественным условием обработки слоя является его нахождение на решетчатой поверхности с достаточно малым сопротивлением газовому потоку. Такие поверхности изготавливаются либо из перфорированных листов, либо из плетеных сеток. Если технологический процесс не предполагает скольжение зерна по решетке (транспортерная лента, например), то оба варианта решет принципиально одинаковы. Скольжение же зерна по решетке, сделанной из сетки, в каждом конкретном случае будет иметь разные характеристики, зависящие и от сетки и от зерна. Скольжение зерна по перфорированному листу близко по своим характеристикам к скольжению по гладкому металлу. Это сближение увеличивается с уменьшением отверстий в решетке, уменьшением их густоты и увеличением среднего размера зерновок в обрабатываемом потоке.

Важным в создании устройства для обработки слоя зерна газами является выбор принципа получения самого слоя заданной толщины. Плоский слой, например на транспортерной ленте, вполне успешно задается подачей зерна на неё через щель. Для поточной обработки зерна газами такие потоки весьма пригодны хотя и требуют дополнительных устройств для заполнения щели и наоборот сбора плоского потока в цилиндрический если того требует следующая операция. 
Однако использование перфорированной транспортерной ленты не представляется рациональным из-за сложностей подачи через нее газа, необходимости привода и других причин. Более приемлем плоский поток, движущийся под действием собственного веса по наклонной решетке. Для практической реализации такого потока необходимо обеспечить достаточную одинаковость его толщины. Как уже отмечалось задать толщину в начале потока можно высотой питающей щели. Далее слой будет двигаться под действием собственного веса, скользя по решетке. Если соблюдается условие установки решетки на угол больше угла скольжения зерна по нему, но меньше угла его естественного откоса, то при наличии подпора внизу на выходе потока толщина слоя по всей его длине будет сохраняться. Условие такого подпора можно записать как:

$Q_{B} \geq Q_{k}$,

где $Q_{\varepsilon}$ - максимально возможный расход в начале потока, кг/с,

$Q_{\kappa}$ - фактический расход в конце потока, кг/с.

Одной из важнейших механических характеристик зерна как сыпучего материала является угол естественного откоса (Трисвятский, 1986). Величина эта достаточно устойчива для того или иного вида материала. Такой же устойчивой величиной является коэффициент трения зерна по стали основному материалу для сельхозтехники. Однако элементы технологических устройств, например решетки, вследствие перфорированности повышают коэффициент трения в сравнении с гладкой поверхностью. Тем не менее, как показывает опыт, у решеток с круглыми отверстиями в полтора - два раза меньшими толщины зерен угол скольжения их слоя существенно меньше угла естественного откоса. Благодаря этому по такой поверхности слой зерна будет скользить не осыпаясь, то есть сохраняя свою толщину.

Его фактический расход в конце потока вполне может задаваться последующим устройством. Таким образом конечное устройство на выходе всей установки может задавать скорость движения слоев на всех наклонных решетках установки.

\section{Цель исследования}

Обосновать конструктивно-технологическую схему установки комбинированного обеззараживания семян зерновых и методику определения параметров ее элементов и режимов функционирования.

\section{Материалы и методы исследования}

Объектом исследования являлся рабочий процесс комбинированного обеззараживания семян зерновых культур электрофизическими воздействиями и обработкой газо-воздушными смесями в установках с гравитационным движением зерна.

Материалами исследования являлись возможные варианты выполнения механизмов этих воздействий, конструктивного исполнения элементов разрабатываемого устройства.

Методами исследования являлись логические построения и анализы с использованием известных закономерностей механики процессов движения и взаимодействия потоков зерна и газа на конических решетках.

\section{Результаты и их обсуждение}

Для разрабатываемой установки обработки семенного зерна комбинированным воздействием конвективного тепла, озонированного воздуха и низкочастотного магнитного поля в цилиндрическом магнитном зазоре из возможных вариантов технологического взаимодействия потоков как наиболее выгодный напрашивается один - скольжение слоя зерна по конической решетке продуваемой снизу подогретым воздухом. Решеток должно быть как минимум две - верхняя распределяющая и ниже под ней собирающая (Рисунок 1).

Устройство, задающее фактический расход потоков по всем элементам установки может иметь различное конструктивное исполнение в зависимости от конкретных условий и состава технологической линии. В представленном простейшем варианте (Рисунок 1) им является сменный выпускной тормозящий конус с выпускным отверстием необходимого диаметра. Этот диаметр, задавая расход, определяет время пребывания зерна в магнитном поле создаваемом трехфазным электромагнитом. В его цилиндрический магнитный зазор зерно попадает из вертикального канала заполняющегося через выпускное отверстие собирающей конической решетки. На эту решетку зерно попадает через дозирующую щель между ней и верхней, распределяющей решеткой, которая в свою очередь заполняется через дозирующую щель патрубка питающего бункера.

Механику образования слоя зерна на конических решетках удобнее всего рассмотреть с конца, то есть с выпускного отверстия собирающей конической решетки. 


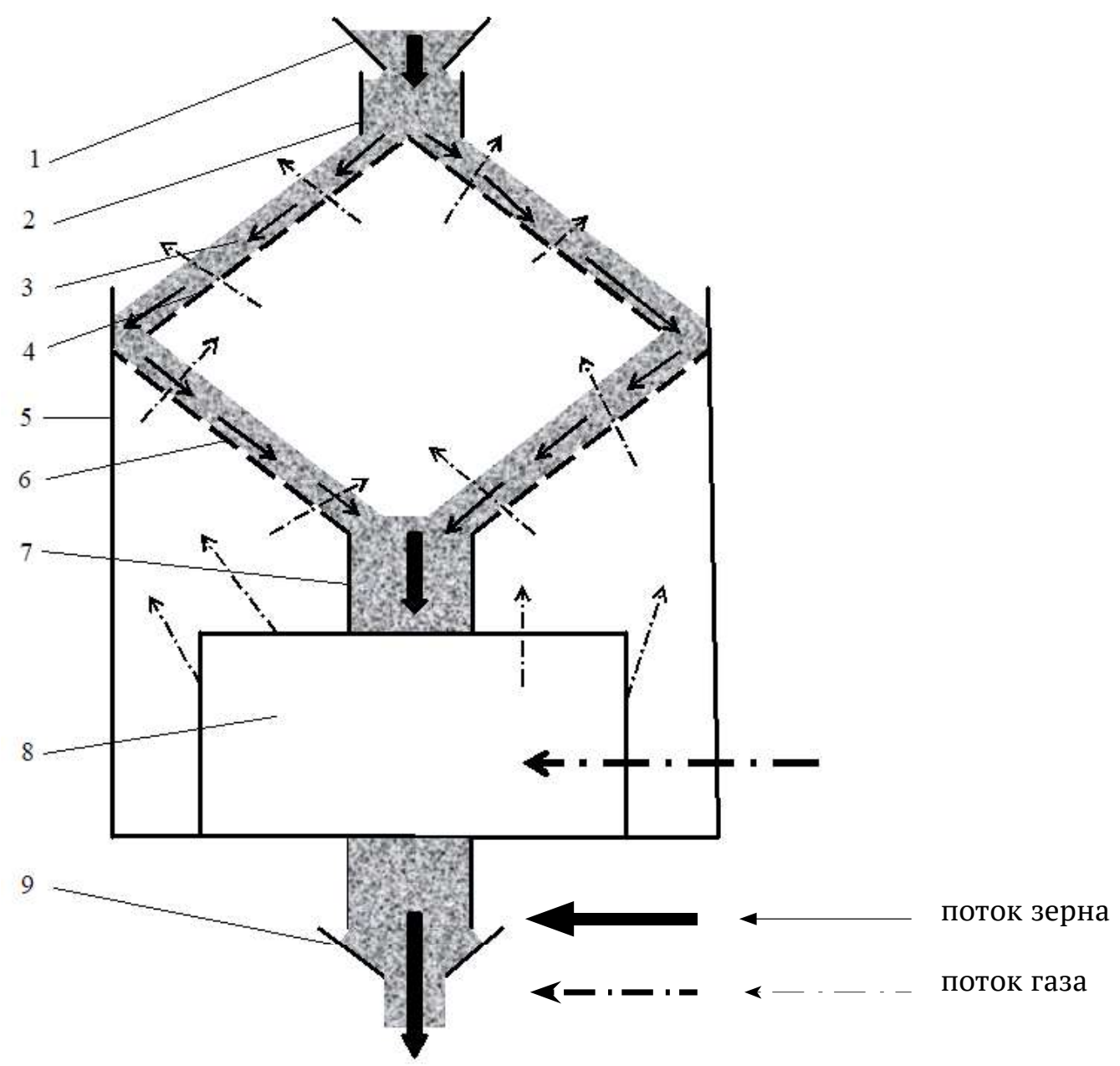

Рисунок 1. Схема устройства магнитно-газовой обработки зерна с коническими решетками: 1 - приемная воронка, 2 - формирующий слой патрубок, 3 - слой зерна, 4 - верхняя коническая решетка, 5 -общий кожух, 6 - нижняя коническая решетка , 7 - соединительный патрубок, 8 - кожух электромагнита, 9 - выпускной поток задающий конус собирающей решетки. После этого приторможенный слой приобретает толщину питающего зазора. Опускаясь вниз и расширяясь слой постоянно пополняется и поддерживает свою толщину за счет осыпания под углом естественного откоса

Первоначально, при закрытом выпуске установки, производится ее заполнение зерном. Выпускной конус, магнитный зазор и вертикальный канал над ним заполняются полностью и создают подпор зерну на выпускном отверстии собирающей решетки. На её поверхности образуется слой начинающий притормаживать поступление зерна через питающую щель.

Притормаживание потока при открытом отверстии выпускного конуса задаёт скорость, поступления зерна на собирающую решетку.

Движение зерна вниз происходит, образно говоря, вследствие последовательного заполнения высвобождающихся объемов начиная с выпускного отверстия. Поддержание толщины слоя обеспечивается тем, что элементы его объема скользят по решетной поверхности, не имея возможности уменьшаться по высоте.

Движение зерна по распределяющей конической решетке представляет собой обратную картину. Через кольцевой зазор на верхушке образуется слой скользящий к нижней кромке и притормаживающийся зерном находящимся на поверхности

Важным условием поддержания толщины слоя является существенное превышение пропускной способности слоеобразующих щелей над пропускной способностью выпускного конуса.

Другим важным требованием к движению зерна по коническим решеткам является достаточная одинаковость времени его пребывания на них, то есть, в зоне пересечения газообразным пото- 
ком. Это достижимо точностями изготовления и установки конической решетки относительно центральной вертикали обеспечивающих одинаковый по контуру выпускного отверстия сход зерна и одинаковое его поступление на нижестоящую коническую решетку.

Условием рационального технологического воздействия в проточном устройстве является некоторое необходимое соотношение взаимодействующих потоков материалов.

В случае обработки потока зерна газовой смесью это условие можно выразить безразмерным соотношением

$G=\left(M_{3} \cdot t\right) /\left(M_{\mathrm{ar}} \cdot t\right)=Q_{3} / Q_{\mathrm{ar}}$,

где $t$ - время взаимодействия потоков (далее принято за 1 ед.), с,

$M_{3}$ - масса зерна, побывавшая в потоке за время $t$, кг,

$M_{a 2}$ - масса активного газового агента прошедшего через зерно за время $t$, кг

$Q_{3}, Q_{\mathrm{ar}}$ - расходы потоковзерна и газового агентов соответственно, кг/с.

Это соотношение в рациональном варианте технологического процесса имеет вполне определенные значения и может быть принято по результатам экспериментальных исследований скорректированных эксплуатационной практикой.

Масса обработанного зерна

$M_{3}=F_{3} \cdot V_{3} \cdot \gamma_{3} \cdot t, \mathrm{Kr}$,

где $F_{3}$ - площадь сечения потока зерна, $\mathrm{M}^{3}$,

$V_{3}$ - скорость потока зерна поданному сечению, м/с, $\gamma_{3}$ - насыпная плотность зерна, кг $/ \mathrm{M}^{3}$,

$t$ - время обработки, с.

Необходимую для обработки массу газа удобно определить с использованием коэффициента усвоения газового агента

$k=M_{\mathrm{ar}} / M_{\mathrm{a}}$,

где $\mathrm{M}_{a z}$ - масса газового агента прошедшего через зерно, кг,

$\mathrm{M}_{a}$ - масса усвоенного зерном газового агента, кг.

Последняя из указанных масс, скорее всего, величина определяемая экспериментально, зависящая от многих конкретных условий. На усвоение прежде всего будет влиять продолжительность воздействия, температуры зерна и газа, концентрация в газе активного вещества, наличие и количество сопутствующих примесей. В случае не высокой стоимости газового агента для повышения надежности процесса желательна избыточность его прохода через зерно.

Из перечисленных факторов влияющих на усвоение агента главным является продолжительность воздействия газа на зерно Его тесное взаимодействие с многими другими факторами должно быть учтено при экспериментальном определении коэффициента усвоения газового агента.

Масса газа прошедшего через слой зерна за единицу времени может быть выражена через концентрацию газового агента в нем.

$M_{\mathrm{r}}=M_{\mathrm{ar}} / \mathrm{c}, \mathrm{Kr} / \mathrm{c}$,

где $c$ - концентрация газового агента в газе в долях.

Это позволяет определить расход потока газа $\Phi_{\text {г }}$ через вентилятор его подачи в зависимости от плотности газа на выходе из него $\gamma_{\text {r }}$, которая как функция развиваемого давления находится по уравнению Менделеева-Клапейрона ${ }^{8}$.

$\Phi_{\mathrm{r}}=\left(M_{\mathrm{a}} /\left(c \cdot \gamma_{\mathrm{r}}\right)\right) \cdot k, \mathrm{M}^{3} / \mathrm{c}$

Таким образом, отношение (2) принимает вид:

$G=\left(\mathrm{F}_{3} \cdot V_{3} \cdot \gamma_{3}\right) /\left(\Phi_{\mathrm{r}} \cdot \mathrm{c} \cdot \gamma_{\mathrm{r}}\right)$.

Определяющим технологическим параметром является продолжительность взаимодействия газового и зернового потоков. Это взаимодействие происходит при гравитационном продвижении зерна по конической решетке. В случае расходящейся решетки движение замедляется, а сходящейся - ускоряется. Считая поток зерна в слое непрерывными, по мере продвижения не меняющимся можно выразить его расход:

$Q_{3}=M_{3} / t=F_{3}^{\mathrm{cp}} \cdot \mathrm{V}_{3}^{\mathrm{cp}} \cdot \gamma_{3}, \mathrm{~K} \Gamma / \mathrm{c}$

Средняя скорость слоя зерна по конической решетке

$V_{3}^{\mathrm{cp}}=Q_{3} /\left(F_{3}^{\mathrm{cp}} \cdot \gamma_{3}\right), \mathrm{M} / \mathrm{c}$

где $F_{3}^{\mathrm{cp}}$ - средняя площадь потока зерна по решетке, определяемая выражением

\footnotetext{
${ }^{8}$ Гороновский, И. Т, Назаренко, Ю. П., \& Некряч, Е. Ф. (1956). Краткий справочник по химии. Киев: Наукова думка.
} 
$F_{3}^{\mathrm{cp}}=\mathrm{a} \cdot L_{\mathrm{cp}}, \mathrm{M}^{3}$

где a - толщина слоя зерна движущегося по решетке, $\mathrm{m}$,

$L_{\mathrm{cp}}$ - средняя длина окружности образующей среднюю площадь сечения потока зерна по конической решетке, определяемая через средний диаметр площади сечения (конического кольца) потока, м.

С использованием размерных характеристик конуса решетки и некотором упрощении выражение площади кругового сечения потока по конусу имеет вид:

$F_{3}^{\mathrm{cp}}=\mathrm{a} \cdot \pi \cdot 1 \cdot \sin 0,5 \psi, \mathrm{M}^{3}$

где $\psi$ - угол конуса обеспечивающий скольжение зерна по решетной поверхности без осыпания под углом естественного откоса то есть он больше угла скольжения $\varphi_{0}$, но меньше угла естественного откоса $\varphi$, град.; $\varphi_{0}>90-\psi / 2>\varphi_{\mathrm{c}}$.

Длиной пути зерна по зоне воздействия газового агента с достаточной точностью можно считать длину образующей конуса усеченного выпускным отверстием. Например, для нижней сходящейся решетки:

$l=\left(d_{\mathrm{B}}-d_{\mathrm{H}}\right) /(2 \cdot \sin 0,5 \psi), \mathrm{M}$,

где $d_{\text {в }}-$ верхний диаметр конуса, м,

$d_{\text {н }}$ - нижний диаметр конуса - диаметр выпускного отверстия, м.

Время пребывания зерна в упомянутой зоне воздействия газового агента выраженное через среднюю скорость:

$t=\left(\pi \cdot a \cdot \gamma_{3} \cdot\left(d_{\mathrm{B}}-d_{\mathrm{H}}\right)^{2}\right) / Q_{3} \cdot(2 \cdot \sin 0,5 \psi)^{2}, \mathrm{C}$

По сути, задача его определения сводится к многофакторному выбору режимов движения зерна и конструктивных параметров конусов и их взаиморасположения. Заданным фактором является общий расход потока зерна и угол между образующими конуса в вертикальном его сечении. К задаваемым (выбираемым), и рассчитываемым следует отнести толщину слоя, диаметры и угол между напротив расположенными образующими конуса решетки.

По аналогии определяются конструктивные размеры распределяющей, верхней конической решетки.
Обозначим последовательность нахождения основных параметров и размеров устройства с коническими решетками.

1. На основании исследований (Пахомов, Максименко, Буханцов, \&Ватутина, 2020) определить расход потока зерна.

2. Опытным путем определить коэффициент усвоения газового агента $k$ для выбранных: толщине слоя зерна, материала решетки, подпора продуваемого газа, температур, влажностей, времени воздействия и других.

3. Определить расход потока газа (6).

4. По выбранному времени воздействия газа, толщине слоя зерна, расходе его потока, с использованием (2), (3), (4), (12), (13) определить размеры конических решеток.

Работоспособность рассмотренного устройства для газового воздействия проверена в разработанной установке ${ }^{9}$ «СИГМА-1» (Максименко, Буханцов, Громакова, 2014; Буханцов, 2015; Ванурин, Максименко, Буханцов, 2015; Пахомов, 2016; Пахомов, Максименко, \&Буханцов, 2017) осуществляющей обеззараживание СВЧ полем, действие которого усиливается предварительным конвективным подогревом зерна от охлаждаемых магнетронов, а также в экспериментальной установке комбинированного обеззараживания низкочастотным магнитным полем и теплом выделяемым электромагнитами балластными резисторами (Пахомов, Максименко, Буханцов, \&Ватутина, 2020).

\section{Выводы}

Для комбинированных электрофизических воздействий рационально использовать устройства с продуваемыми коническими решетками. В них достижимо эффективное, достаточно одинаковое усвоение зерном газового агента. Предложенные зависимости позволяют определять основные параметры и режимы работы установки с коническими решетками для комбинированных обеззараживающих электрофизических и газовых воздействий на зерно.

\section{Финансирование}

Работа выполнена в рамках Программы фундаментальных научных исследований государственных академий наук на 2019-2021 гг.

\footnotetext{
9 Пахомов, В. И., Паховом А. И., Буханцов, К. Н., \& Максименко, В. А. (2018). Патент № 2640288 РФ. Способ комбинированного обеззараживания зерна и семян с использованием СВЧ-энергии. Зерноград: ФГБНУ СКНИИМЭСХ.
} 
«Фундаментальные проблемы и принципы разработки интенсивных технологий и энергонасыщенной техники нового поколения производства основных групп продовольствия» (шифр темы НИР 0706-2019-0006 «Разработать новые технологические принципы, процессы и технические средства в системе переработки и обеззараживания зерна и семян»).

\section{Литература}

Андреев, С. А. (1987). Установка для СВЧ-обработки семян (Автореферат дисс. ... канд. техн. наук). М.: МИИСП им. В.П. Горячкина.

Андрющенко, Ю. А., Буханцов, К. Н. (2007). Исследование процесса обеззараживания зерновых материалов от плесневых грибов разными способами на основе озонирования. В Экология $u$ сельскохозяйственная техника: Сборник научных трудов по Материалам 5-й Междунарадной научно-практической конференции (т. 2, с. 216-225). СПб.: Северо-Западный НИИМЭСХ РАСХН.

Буханцов, К. Н. (2015). Математическая модель процесса обеззараживания увлажненного водой зерна сочетанием конвективного нагрева и обработки электромагнитным полем сверхвысокой частоты. Электротехнические комплексы и системы управления, 1, 9-23.

Буханцов, К. Н. (2012). Озон и аэроионы: возможности и проблемы использования для сушки зерна. Хранение и переработка сельхозсырья, 9, $13-16$.

Ванурин, В. Н., Максименко, В. А., \& Буханцов, К. Н. (2015). Выбор привода отгрузочного шнека установки СВЧ-обеззараживания «СИГМА-1». Вестник АПК Ставрополья, 4, 18-23.

Васильев, А. А. (2018). Обоснование режимов послеуборочного обеззараживания зерна с использованием поля СВЧ (Дисс. канд. техн. наук). М.: Всероссийский научно-исследовательский институт электрификации сельского хозяйства.

Глущенко, Л. Ф., \& Глущенко, Н. А. (2003). Интенсификация процессов пищевых и сельскохозяйственных производств озоно-воздушными смесями. Великий Новгород: Новгородский государственный университет им. Ярослава Мудрого.

Голубкович, А. В., Тимошек, А. С., \& Чеботарёв, В. П. (2002). Особенности комбинированной сушки зерна с применением озоно-воздушных смесей. В Здоровье - питание - биологические ресурсы: Материалы Международной научно-практической конференции посвященной. 125-летию со дня рождения акад. Н. В. Рудницкого (т. 2, с. 140-146). Киров: Зональный научно-исследова- тельский институт сельского хозяйства СевероВостока им. Н. В. Рудницкого.

Голубкович, А. В., \& Чижиков, А. Г. (2005). Сушка семян и зерна озоно-воздушной смесью. Техника в сельском хозяйства, 1, 37-40.

Дубровин, А. В. (2017). Технологически или экономически оптимальные инфракрасная и кондуктивная сушка и озонирование при обеззараживании зерна и комбикормов для птицы. Вестник ВИЭСХ, 2, 32-44.

Максименко, В. А., Андреев, А. И., Громакова, Л. В., \&Парапонов А.А. Оценка влияния электрофизических обработок семян пшеницы на прочность соломы. В Ресурсосберегающие технологии: возделывание и переработка сельскохозяйственных культур: Сборник научных трудов инновационные проекты в АПК (с. 243249). Зерноград: ВНИПТИМЭСХ.

Максименко, В. А., Буханцов, К. Н., \& Громакова, Л. В. (2014). Особенности автоматизации СВЧ-модуля на бытовых магнетронах «СИГМА-1». Инновации в сельском хозяйстве, 4, 128-134.

Пахомов, А. И. (2016). Комбинированная технология обеззараживания зерна. Хранение и переработка зерна, 2, 27-29.

Пахомов, А. И., Максименко, В. А., Буханцов, К. Н., \& Ватутина, Н. П. (2020). Комбинированный конвективно-магнитный метод обеззараживания семенных материалов в АПК. Техника и оборудование для села, 3, 33-36. https://doi. org/10.33267/2072-9642-2020-3-33-36

Пахомов, А. И., Максименко, В. А., \& Буханцов, К. Н. (2017). Энергетическая оценка комплекта нового оборудования для конвективно-сверхвысокочастотного и низкоконцентрационного химического обеззараживания зерна и семян. Техника и оборудование для села, $11,27-31$.

Пахомов, В. И., \& Буханцов, К. Н. (2011). Реализация технологий комбинированной сушки, обеззараживания и стимулирования посевных свойств зерна и семян на базе установки «ЭЛЕКТА-1». В Научно-технический прогресс в сельскохозяйственном производстве: Материалы Международной научно-практической конференции (т. 1, с. 196-207). Минск: РУП НПЦ НАН Беларуси по механизации сельского хозяйства.

Пахомов, В. И., Газалов, В. С., \&Буханцов, К. Н. (2019). Регрессионная математическая модель двухэтапной комбинированной электротехнологии высокотемпературной конвективной сушки и озоновоздушной обработки зерна. Тракторы и сельхозмашины, 1, 81-95. https://doi. org/10.31992/0321-4443-2019-1-81-95 
Пахомов, В. И., Максименко, В. А., \& Буханцов, К. Н. (2013). Энергосберегающая технология высокотемпературной конвективной сушки и озоновоздушной обработки зерна. Хранение $u$ переработка сельхозсырья, 5, 19-25.

Пахомов, В. И., Пахомов, А. И., \& Максименко, В. А. (2015). Новая технология обеззараживания зерна с применением СВЧ-энергии. Хлебопродукты, 9, 63-65.

Сюсюра, Н. А. (2003). Обоснование параметров электроактивированного раствора и режимов работы без диафрагменного электроактиватора в технологии предпосевной обработки семян зерновых культур(Автореферат дисс. ... канд. техн. наук). Зерноград: АЧГАА.

Трисвятский, Л. А. (1986). Хранение зерна (5-е изд., перераб). М.: Агропромиздат.

Цугленок, Н. В., Цугленок, Г. И., \& Шахматов С.Н. (1989). Интенсификация тепловых процессов подготовки семян к посеву энергией ВЧ и СВЧ. М.: ВО Агропромиздат.

Червяков, А. В., Курзенков, С. В., Циркунов, А. С., \& Крупенин, П. Ю. (2008). Экспериментальное исследование распределения температурного поля в зерновом материале при обработке СВЧполем. В Инновационные технологии и технические средства в полеводстве юга России: Сборник научных трудов Международной научно-практической конференции «Инновационные техно- логии для АПК России» (с. 262-272). Зерноград: ВНИПТИМЭСХ.

Baskakov, I. V., Orobinsky, V. I., Gulevsky, V. A., Gievsky, A. M., \& Chernyshov, A. V. (2020). Influence of ozonation in seed storage on corn grain yield and its quality. In IOP Conference Series: Earth and Environmental Science. Russian Conference on Technological Solutions and Instrumentation for Agribusiness (TSIA-2019) (vol. 488, 012007). Bristol, UK: IOP Publishing Ltd. https://doi. org/10.1088/1755-1315/488/1/012007

Cwiklinski, M., von Hörsten, D., Lücke, W., \& Wolf, G. (2001). Alternativen zur chemischen Beizung. Saatgutbehandlung mit Mikrowellen- und Hochfrequenzenergie. Landtechnik, 56(1), 28-29. https://doi.org/10.15150/lt.2001.1697

Raila, A., Lugauskas, A., Steponavicius, D., Railiene, M., Steponaviciene, A., \& Zvicevicius, E. (2006). Application of ozone for reduction of mycological infection in wheat grain. Annals of Agricultural and Environmental Medicine, 13(2), 287-294.

Savi, G. D., Piacentini, K. C., Bittencourt, K. O., \& Scussel, V. M. (2014). Ozone treatment efficiency on fusarium graminearum and deoxynivalenol degradation and its effects on whole wheat grains (TriticumAestivum L.) quality and germination. Journal of Stored Products Research, 59, 245-253. https://doi.org/10.1016/j.jspr.2014.03.008 


\title{
Conic Floors in the Seeds Treatment Devices
}

\author{
Vladimir A. Maksimenko \\ Northern-Caucasian Scientific Research Institute \\ of Mechanization and Electrification of Agriculture \\ Federal State Budgetary Scientific Institution \\ "Agricultural research center «Donskoy» \\ (NCRIMEA FSBSI «ASC «Donskoy») \\ 14, Leninastr., Zernograd, Rostov region, 347740, Russian Federation \\ E-mail: elektro_skniimesh.rashn@mail.ru
}

\begin{abstract}
On the basis of the previously revealed efficiency of grain crops compound aseptic influences, it is suggested their fulfillment in a single device. The analysis of the possible constructive variants of the units for grain disinfection was carried out on the basis of treatments with low-frequency or super-high frequency magnetic fields in aggregate with convection heat action. By the results of this analysis the choice has been made in favour of a unit designed for grain treatment period with decontaminating gas agents and equipped with conical grids. Its process flowsheet has been worked out too. The constructive-process flowsheet of the unit for combined crops grain disinfection has been validated and either its elements' method of characterization or modes of operation have been worked out. Conditions of rational correlation of gas and grain flows in a unit have been considered, and main mathematical expressions have been suggested for estimation of their charges. If grain flow discharge is considered to bea determining factor in the area of electro physical influence, as the main sizes of conical grids and their positional relationship as time of grain staying under influence of decontaminating gas flow can be determined according to offered expressions. Inverse solutions can be made on the basis of these expressions, for example, flows parameters matching for rational use of available grids of certain sizes. Presented dependences and methodic guidelines will be useful at designing the equipment with conic floors.
\end{abstract}

Keywords: grain, gas, flow, floor, cone, layer, disinfection

\section{References}

Andreev, S. A. (1987). Ustanovka dlya SVCh-obrabotki semyan (Avtoreferat diss. ... kand. tekhn. nauk) [Installation for the SHF treatment of seeds (Abstract of $\mathrm{PhD}$ )]. Moscow: MIISP im. V.P. Goryachkina. Moskva.

Andryushchenko, Yu. A., Bukhantsov, K. N. (2007). Issledovanie protsessa obezzarazhivaniya zernovykh materialov ot plesnevykh gribov raznymi sposobami na osnove ozonirovaniya [The research of grain materials' disinfection process for molds with different methods on the basis of ozonization]. In Ekologiya i sel'skokhozyaistvennaya tekhnika: Sbornik nauchnykh trudov po Materialam 5-i Mezhdunaradnoi nauchno-prakticheskoi konferentsii [Ecology and agricultural technics: Collected papers of the 5th International theoretical and practical conference] (vol. 2, pp. 216-225). S-Petersburg: Severo-Zapadnyi NIIMESKh RASKhN.

Bukhantsov, K. N. (2015). Matematicheskaya model' protsessa obezzarazhivaniya uvlazhnennogo vodoi zerna sochetaniem konvektivnogo nagreva i obrabotki elektromagnitnym polem sverkh- vysokoi chastity [A mathematical model of moistened grain disinfection process by combination of convective heating and treatment with electromagnetic field of microwave frequency]. Elektrotekhnicheskie kompleksy i sistemy upravleniya [Electro technical complexes and control systems], $1,9-23$.

Bukhantsov, K. N. (2012). Ozon i aeroiony: vozmozhnosti i problemy ispol'zovaniya dlya sushki zerna [Ozon and air ions: their capabilities and problems for grain dryer]. Khranenie i pererabotka sel'khozsyr'ya [Storage and Processing of Farm Products], 9, 13-16.

Vanurin, V. N., Maksimenko, V. A., \& Bukhantsov, K. N. (2015). Vybor privoda otgruzochnogo shneka ustanovki SVCh-obezzarazhivaniya «SIGMA-1» [Choice of dispatch screw drive for the disinfection UHF module "SIGMA-1"]. Vestnik APK Stavropol'ya [Agricultural Bulletin of Stavropol Region], 4, 18-23.

Vasil'ev, A. A. (2018). Obosnovanie rezhimov posleuborochnogo obezzarazhivaniya zerna s ispol'zovaniem polya SVCh (Diss. kand. tekhn. nauk) [The validation of afterharvesting grain disinfection modes using SHF field ( $\mathrm{PhD}$ dissertation)]. Moscow: 
Vserossiyskiy nauchno-issledovatel'skiy institut elektrifikatsii sel'skogo khozyaystva.

Glushchenko, L. F., \& Glushchenko, N. A. (2003). Intensifikatsiya protsessov pishchevykh i sel'skokhozyaistvennykh proizvodstv ozono-vozdushnymi smesyami [Intensification of food and agricultural production processes with ozone-air mixtures]. Velikii Novgorod: Novgorodskii gosudarstvennyi universitet im. Yaroslava Mudrogo.

Golubkovich, A. V., Timoshek, A. S., \& Chebotarev, V. P. (2002). Osobennosti kombinirovannoi sushki zerna s primeneniem ozono-vozdushnykh smesei [Features of combined drying of grain using ozone-air mixtures]. In Zdorov'e - pitanie - biologicheskie resursy: Materialy Mezhdunarodnoi nauchno-prakticheskoi konferentsii posvyashchennoi. 125-letiyu so dnya rozhdeniya akad. N. V. Rudnitskogo [Health - Nutrition - Biological Resources. The International theoretical and practical conference materials to. 125th anniversary of the birth of Acad. N.V. Rudnitsky] (vol. 2, pp. 140-146). Kirov: Zonal'nyi nauchno-issledovatel'skii institut sel'skogo khozyaistva Severo-Vostoka im. N. V. Rudnitskogo.

Golubkovich, A. V., \& Chizhikov, A. G. (2005). Sushka semyan i zerna ozono-vozdushnoi smes'yu [Drying of seeds and grains with an ozone-air mixture]. Tekhnika v sel'skom khozyaistva [Agricultural Machinery], 1, 37-40.

Dubrovin, A. V. (2017). Tekhnologicheski ili ekonomicheski optimal'nye infrakrasnaya i konduktivnaya sushka i ozonirovanie pri obezzarazhivanii zerna i kombikormov dlya ptitsy [Technologically or economically optimal infrared and conductive drying and ozonization at grain disinfection and combined feed for birds]. Vestnik VIESKh [Bulletin All-Russian Research Institute of Agricultural Electrification], 2, 32-44.

Maksimenko, V. A., Andreev, A. I., Gromakova, L. V., \& Paraponov A.A. Otsenka vliyaniya elektrofizicheskikh obrabotok semyan pshenitsy na prochnost' solomy [The evaluation of wheat seeds electro-physical treatment influence on straw strength]. In Resursosberegayushchie tekhnologii: vozdelyvanie i pererabotka sel'skokhozyaistvennykh kul'tur: Sbornik nauchnykh trudov innovatsionnye proekty $v$ APK [Alternative technologies: agricultural crops cultivation and treatment: Collected scientific papers of the International Scientific Technical Conference: "Alternative technologies and innovative designs in AIC»] (pp. 243-249). Zernograd: VNIPTIMESKh.

Maksimenko, V. A., Bukhantsov, K. N., \& Gromakova, L. V. (2014). Osobennosti avtomatizatsii SVChmodulya na bytovykh magnetronakh «SIGMA-1» [Automation features of the UHF module at con- sume magnetrons "SIGMA-1"]. Innovatsii $v$ sel'skom khozyaistve [Agricultural Innovation], 4, 128-134.

Pakhomov, A. I. (2016). Kombinirovannaya tekhnologiya obezzarazhivaniya zerna [A combined technology of grain disinfection]. Khranenie i pererabotka zerna [Grain Storage and Treatment], 2, 2729.

Pakhomov, A. I., Maksimenko, V. A., Bukhantsov, K. N., \& Vatutina, N. P. (2020). Kombinirovannyi konvektivno-magnitnyi metod obezzarazhivaniya semennykh materialov v APK [Combined convective-magnetic method of seeds' material disinfection in AIC]. Tekhnika i oborudovanie dlya sela [Machinery and equipment for rural areas], 3, 33-36. https://doi.org/10.33267/2072-9642-20203-33-36

Pakhomov, A. I., Maksimenko, V. A., \& Bukhantsov, K. N. (2017). Energeticheskaya otsenka komplekta novogo oborudovaniya dlya konvektivno-sverkhvysokochastotnogo i nizkokontsentratsionnogo khimicheskogo obezzarazhivaniya zerna i semyan [Energy estimation of the new equipment set for convective microwave and low-concentration chemical disinfection of grain and seeds]. Tekhnika i oborudovanie dlya sela [Machinery and equipment for rural areas], 11, 27-31.

Pakhomov, V. I., \& Bukhantsov, K. N. (2011). Realizatsiya tekhnologii kombinirovannoi sushki, obezzarazhivaniya i stimulirovaniya posevnykh svoistv zerna i semyan na baze ustanovki «ELEKTA-1» [Implementation of combined drying, disinfection and stimulation of grain and seeds sowing characteristics technologies on the basis of «ELEKTA-1» unit]. In Nauchno-tekhnicheskii progress $v$ sel'skokhozyaistvennom proizvodstve: Materialy Mezhdunarodnoi nauchno-prakticheskoi konferentsii [Scientific-technical progress in agricultural production: The International theoretical and practical conference materials] (vol. 1, pp. 196-207). Minsk: RUP NPTs NAN Belarusi po mekhanizatsii sel'skogo khozyaistva.

Pakhomov, V. I., Gazalov, V. S., \& Bukhantsov, K. N. (2019). Regressionnaya matematicheskaya model' dvukhetapnoi kombinirovannoi elektrotekhnologii vysokotemperaturnoi konvektivnoi sushki i ozonovozdushnoi obrabotki zerna [A regression mathematical model of two-stage combined high-temperature convective dryer, using electrical technology, and ozone-air grain treatment]. Traktory $i$ sel'khozmashiny [Tractors and agricultural machines], 1, 81-95. https://doi. org/10.31992/0321-4443-2019-1-81-95

Pakhomov, V. I., Maksimenko, V. A., \& Bukhantsov, K. N. (2013). Energosberegayushchaya tekhnologiya vysokotemperaturnoi konvektivnoi su- 
shki i ozonovozdushnoi obrabotki zerna [The energy-efficient technics of high-temperature convective dryer and ozone-air crop treatment]. Khranenie i pererabotka sel'khozsyr'ya [Storage and Processing of Farm Products], 5, 19-25.

Pakhomov, V. I., Pakhomov, A. I., \& Maksimenko, V. A. (2015). Novaya tekhnologiya obezzarazhivaniya zerna s primeneniem SVCh-energii [A new technique of grain disinfection with SHF energy]. Khleboprodukty [Bread produce], 9, 63-65.

Syusyura, N. A. (2003). Obosnovanie parametrov elektroaktivirovannogo rastvora $i$ rezhimov raboty bezdiafragmennogo elektroaktivatora $v$ tekhnologii predposevnoi obrabotki semyan zernovykh kul'tur (Avtoreferat diss. ... kand. tekhn. nauk) [The validation of electroactivated solution parameters and diaphragmless electro activator's operating regime in the technology of grain seeds preplant treatment (Abstract of PhD]. Zernograd: AChGAA.

Trisvyatskii, L. A. (1986). Khranenie zerna [Grain storage] (5th ed.). Moscow: Agropromizdat.

Tsuglenok, N. V., Tsuglenok, G. I., \& Shakhmatov S.N. (1989). Intensifikatsiya teplovykh protsessov podgotovki semyan $k$ posevu energiei VCh $i$ SVCh [Intensification of heat processes of seeds preparation for sowing with HF and SHF]. Moscow: VO Agropromizdat.

Baskakov, I. V., Orobinsky, V. I., Gulevsky, V. A., Gievsky, A. M., \& Chernyshov, A. V. (2020). Influence of ozonation in seed storage on corn grain yield and its quality. In IOP Conference Series: Earth and Environmental Science. Russian Conference on Technological Solutions and
Instrumentation for Agribusiness (TSIA-2019) (vol. 488, 012007). Bristol, UK: IOP Publishing Ltd. https://doi.org/10.1088/1755-1315/488/1/012007

Chervyakov, A. V., Kurzenkov, S. V., Tsirkunov, A. S., \& Krupenin, P. Yu. (2008). Eksperimental'noe issledovanie raspredeleniya temperaturnogo polya $\mathrm{V}$ zernovom materiale pri obrabotke SVCh-polem [Experimental study of temperature field's distribution in grain material at SHF field treatment]. In Innovatsionnye tekhnologii i tekhnicheskie sredstva v polevodstve yuga Rossii: Sbornik nauchnykh trudov Mezhdunarodnoi nauchno-prakticheskoi konferentsii «Innovatsionnye tekhnologii dlya APK Rossii» [Innovation techniques and technical means in field husbandry of Russia's South: Collected scientific papers of The International theoretical and practical conference «Innovation techniques for the AIC of Russia»] (pp. 262-272). Zernograd: VNIPTIMESKh.

Cwiklinski, M., von Hörsten, D., Lücke, W., \& Wolf, G. (2001). Alternativen zur chemischen Beizung. Saatgutbehandlung mit Mikrowellen- und Hochfrequenzenergie. Landtechnik, 56(1), 28-29. https://doi.org/10.15150/lt.2001.1697

Raila, A., Lugauskas, A., Steponavicius, D., Railiene, M., Steponaviciene, A., \& Zvicevicius, E. (2006). Application of ozone for reduction of mycological infection in wheat grain. Annals of Agricultural and Environmental Medicine, 13(2), 287-294.

Savi, G. D., Piacentini, K. C., Bittencourt, K. O., \& Scussel, V. M. (2014). Ozone treatment efficiency on fusarium graminearum and deoxynivalenol degradation and its effects on whole wheat grains (TriticumAestivum L.) quality and germination. 